University of Nebraska - Lincoln

DigitalCommons@University of Nebraska - Lincoln

Public Health Resources

Public Health Resources

2016

Standardizing the influenza neuraminidase inhibition assay among United States public health laboratories conducting virological surveillance

M. Okomo-Adhiambo

Centers for Disease Control and Prevention (CDC), Atlanta, GA

V.P. Mishin

Centers for Disease Control and Prevention (CDC), Atlanta, GA

K. Sleeman

Centers for Disease Control and Prevention (CDC), Atlanta, GA

E. Saguar

California Department of Public Health (CDPH), Richmond, CA

H. Guevara

California Department of Public Health (CDPH), Richmond, CA

See next page for additional authors

Follow this and additional works at: http://digitalcommons.unl.edu/publichealthresources

Okomo-Adhiambo, M.; Mishin, V.P.; Sleeman, K.; Saguar, E.; Guevara, H.; Reisdorf, E.; Griesser, R.H.; Spackman, K.J.; Mendenhall, M.; Carlos, M.P.; Healey, B.; St. George, K.; Laplante, J.; Aden, T.; Chester, S.; Xu, X.; and Gubareva, L.V., "Standardizing the influenza neuraminidase inhibition assay among United States public health laboratories conducting virological surveillance" (2016). Public Health Resources. 456.

http://digitalcommons.unl.edu/publichealthresources/456

This Article is brought to you for free and open access by the Public Health Resources at DigitalCommons@University of Nebraska - Lincoln. It has been accepted for inclusion in Public Health Resources by an authorized administrator of DigitalCommons@University of Nebraska - Lincoln. 


\section{Authors}

M. Okomo-Adhiambo, V.P. Mishin, K. Sleeman, E. Saguar, H. Guevara, E. Reisdorf, R.H. Griesser, K.J. Spackman, M. Mendenhall, M.P. Carlos, B. Healey, K. St. George, J. Laplante, T. Aden, S. Chester, X. Xu, and L.V. Gubareva 


\title{
Standardizing the influenza neuraminidase inhibition assay among United States public health laboratories conducting virological surveillance
}

\author{
M. Okomo-Adhiambo a, V.P. Mishin ${ }^{\text {a }}$, K. Sleeman ${ }^{\text {a, }}{ }^{1}$, E. Saguar ${ }^{\text {b }}$, H. Guevara ${ }^{\text {b }}$, \\ E. Reisdorf ${ }^{\text {c }}$, R.H. Griesser ${ }^{\text {c }}$, K.J. Spackman ${ }^{\mathrm{d}}$, M. Mendenhall ${ }^{\mathrm{d}}$, M.P. Carlos ${ }^{\mathrm{e}}$, B. Healey ${ }^{\mathrm{e}}$, \\ K. St. George ${ }^{\text {f }}$ J. Laplante ${ }^{\text {f }}$, T. Aden ${ }^{\text {g, }}{ }^{2}$, S. Chester ${ }^{\mathrm{g}}, \mathrm{X}$. Xu ${ }^{\text {a }}$, L.V. Gubareva ${ }^{\mathrm{a},{ }^{*}}$ \\ a Influenza Division, NCIRD, Centers for Disease Control and Prevention (CDC), Atlanta, GA, USA \\ b California Department of Public Health (CDPH), Richmond, CA, USA \\ ${ }^{c}$ Wisconsin State Laboratory of Hygiene (WSLH), Madison, WI, USA \\ ${ }^{\mathrm{d}}$ Unified State Laboratories: Public Health (USLPH), Taylorsville, UT, USA \\ e Maryland Department of Health and Mental Hygiene (MD DHMH) Laboratories Administration, Baltimore, MD, USA \\ ${ }^{\mathrm{f}}$ Wadsworth Center, New York State Department of Health (NYSDOH), Albany, NY, USA \\ ${ }^{g}$ Association of Public Health Laboratories (APHL), Silver Spring, MD, USA
}

\section{A R T I C L E I N F O}

\section{Article history:}

Received 13 October 2015

Received in revised form

11 January 2016

Accepted 15 January 2016

Available online 22 January 2016

\section{Keywords:}

Assay standardization

Neuraminidase inhibition

Oseltamivir

Zanamivir

Peramivir

\begin{abstract}
A B S T R A C T
Background: Monitoring influenza virus susceptibility to neuraminidase (NA) inhibitors (NAIs) is vital for detecting drug-resistant variants, and is primarily assessed using NA inhibition (NI) assays, supplemented by NA sequence analysis. However, differences in NI testing methodologies between surveillance laboratories results in variability of $50 \%$ inhibitory concentration $\left(\mathrm{IC}_{50}\right)$ values, which impacts data sharing, reporting and interpretation. In 2011, the Centers for Disease Control and Prevention (CDC), in collaboration with the Association for Public Health Laboratories (APHL) spearheaded efforts to standardize fluorescence-based NI assay testing in the United States (U.S.), with the goal of achieving consistency of $\mathrm{IC}_{50}$ data.

Methods: For the standardization process, three participating state public health laboratories (PHLs), designated as National Surveillance Reference Centers for Influenza (NSRC-Is), assessed the NAI susceptibility of the 2011-12 CDC reference virus panel using stepwise procedures, with support from the CDC reference laboratory. Next, the NSRC-Is assessed the NAI susceptibility of season 2011-12 U.S. influenza surveillance isolates $(n=940)$, with a large subset $(n=742)$ tested in parallel by CDC. Subsequently, U.S. influenza surveillance isolates $(\mathrm{n}=9629)$ circulating during the next three influenza seasons $(2012-15)$, were independently tested by the three NSRC-Is $(n=7331)$ and CDC $(n=2298)$. Results: The NI assay $\mathrm{IC}_{50} \mathrm{~S}$ generated by respective NSRC-Is using viruses and drugs prepared by CDC were similar to those obtained with viruses and drugs prepared in-house, and were uniform between laboratories. $\mathrm{IC}_{50}$ s for U.S. surveillance isolates tested during four consecutive influenza seasons (2011 -15 ) were consistent from season to season, within and between laboratories.

Conclusion: These results show that the NI assay is robust enough to be standardized, marking the first time $\mathrm{IC}_{50}$ data have been normalized across multiple laboratories, and used for U.S. national NAI susceptibility surveillance.
\end{abstract}

Published by Elsevier B.V.

\footnotetext{
* Corresponding author. Mail Stop G-16, 1600 Clifton Road, Atlanta, GA 30333, USA.

E-mail address: lgubareva@cdc.gov (L.V. Gubareva).

${ }^{1}$ Present affiliation: Division of Global HIV/AIDS, CGH, CDC, Atlanta, GA, USA.

2 Present affiliation: Battelle, Atlanta, GA, USA.
}

\section{Introduction}

Neuraminidase (NA) inhibitors (NAIs) are currently the only class of antiviral drugs recommended by Centers for Disease Control and Prevention (CDC) for the control of influenza infections, due to widespread resistance to the M2 blockers (adamantanes) 
(Deyde et al., 2007). In 1999, orally administered oseltamivir and inhaled zanamivir were approved by the United States (U.S.) Food and Drug Administration (FDA) for control of influenza type A and $B$ infections. In December 2014, a third NAI, intravenous peramivir (Shetty and Peek, 2012), was FDA-approved. Peramivir is also licensed in Japan, South Korea and China, while inhaled laninamivir (Yamashita et al., 2009) is approved in Japan. Intravenous zanamivir has been provided for compassionate use in recent years, and is undergoing evaluation for treatment of hospitalized patients with severe influenza (https://clinicaltrials.gov/show/NCT01231620).

During initial post-marketing years, monitoring influenza virus susceptibility to NAIs was carried out by a central laboratory contracted by the Neuraminidase Inhibitor Susceptibility Network (NISN) which utilized chemiluminescence- and fluorescence-based NI assays (Wetherall et al., 2003). Later, monitoring NAIsusceptibility became an integral part of virological surveillance within the WHO Global Influenza Surveillance and Response System (WHO-GISRS), where both functional (NA inhibition) and sequence-based (pyrosequencing, real time RT-PCR, Sanger) assays have been utilized to conduct drug susceptibility monitoring worldwide (Monto et al., 2006; Meijer et al., 2014). Following the FDA's approval of zanamivir and oseltamivir, CDC implemented the $\mathrm{NI}$ assay, first using a chemiluminescence-based (Mungall et al., 2004), then a fluorescence-based methodology (OkomoAdhiambo et al., 2013). The NI assay testing is done for the purpose of monitoring changes in the baseline NAI susceptibility of circulating influenza viruses.

Historically, there has been significant variability in $\mathrm{IC}_{50}$ data (the drug concentration required to inhibit $50 \%$ of viral NA enzyme activity), due to factors such as variations in assay choice and/or assay conditions. The lack of standardization in NI assay methodologies and the resulting $\mathrm{IC}_{50}$ variability has been a challenge in sharing and interpreting $\mathrm{IC}_{50}$ data among laboratories. In 2012, in efforts to harmonize the interpretation and reporting of $\mathrm{IC}_{50}$ data, the WHO Expert Working Group for GISRS on Surveillance of Antiviral Susceptibility (WHO-AVWG) agreed on criteria to define influenza viruses as exhibiting normal, reduced (RI) or highly reduced (HRI) NA inhibition, based on the fold change of their $\mathrm{IC}_{50}$ compared to reference $\mathrm{IC}_{50}$ values $(\mathrm{WHO}, 2012)$. These criteria have been helpful in interpretation and reporting of NI assay data generated by different WHO Collaborating Centers (OkomoAdhiambo et al., 2014; Takashita et al., 2014, 2015a), and for providing annual global updates (Meijer et al., 2014; Takashita et al., 2015b). Viruses of N1 subtype carrying the H275Y substitution in the NA (H274Y in N2 subtype) and A(H3N2) viruses carrying E119V or R292K substitutions consistently demonstrate HRI by oseltamivir in NI assays (Meijer et al., 2014; Okomo-Adhiambo et al., 2014; Takashita et al., 2015b).

In the summer of 2011, the CDC spearheaded efforts to standardize influenza NI testing within the U.S., in collaboration with the Association for Public Health Laboratories (APHL) and several state public health laboratories (PHLs), with the goal of minimizing $\mathrm{NI}$ assay $\mathrm{IC}_{50}$ data variability within and among surveillance laboratories, as well as increasing the US capacity to monitor the NAI susceptibility of influenza viruses. Three PHLs, designated as National Surveillance Reference Centers for Influenza (NSRC-Is), namely, the California Department of Public Health (CDPH), Richmond, CA; Unified State Laboratories, Public Health (USLPH), Taylorsville, UT; and the Wisconsin State Laboratory of Hygiene (WSLH), Madison, WI, participated in the "Project for Standardization of NAI Susceptibility Testing," through a step-wise procedure developed by the CDC. In April 2012, Maryland Department of Health and Mental Hygiene (MD DHMH) Laboratories Administration also participated in an additional NI Standardization Project, but was not selected as a NSRC-I.
After successfully completing the standardization process, the three NSRC-Is performed NI assay testing on U.S. influenza surveillance specimens collected during the 2011-12 season, and three subsequent seasons, 2012-13, 2013-14, and 2014-15. The NI assay testing activity was added to an ongoing APHL contract for influenza virus isolation, collectively referred to as the "VI/NI Project." At CDC, standardized $\mathrm{IC}_{50}$ data generated by the NSRC-Is were further analyzed based on criteria of the WHO-AVWG (WHO, 2012) to identify viruses with RI or HRI, which were genetically analyzed by pyrosequencing and/or conventional NA sequence analysis to determine underlying NA changes responsible for elevated $\mathrm{IC}_{50} \mathrm{~s}$. Viruses with markers previously associated with resistance to $\mathrm{NAI}(\mathrm{s})$ were reported as NAI-resistant to the WHO GISRS and in the U.S. influenza virological surveillance Report (FluView) (http://www.cdc.gov/flu/weekly/).

This report describes results of the NI assay standardization project performed on the 2011-12 CDC reference virus panel by three NSRC-Is (CDPH, USLPH and WSLH), as well as NI assay data for U.S. influenza surveillance isolates they tested during seasons 2011-15. These results suggest that NAI drug susceptibility data generated in the NI assay can be interpreted and shared in a consistent, reproducible manner when detailed procedures and reference materials are used in assay implementation.

\section{Materials and methods}

\subsection{Training}

Prior to the standardization process, participating laboratories received training on the fluorescent NI assay by CDC laboratorians, through lectures and hands-on instruction. The training course, conducted in April 2011, was sponsored by the APHL, CDC and National Laboratory Training Network (NLTN), and comprised preand post-test knowledge assessment; background information on influenza and drug susceptibility testing; NI assay workflow; reagent and drug preparation; determination of virus dilutions for use in the NI assay; identification of acceptable NI assay results; equipment operation; $\mathrm{IC}_{50}$ data analysis and interpretation.

\subsection{Viruses}

The 2011-12 CDC reference panel (Table 1) comprising wildtype and variant virus pairs of seasonal influenza types/subtypes, as well as surveillance isolates circulating during the 2011-14 influenza seasons were propagated in Madin-Darby canine kidney (MDCK) cells provided by CDC. Since October, 2014 (season 2014-15) influenza $\mathrm{A}(\mathrm{H} 3 \mathrm{~N} 2)$ viruses are propagated in MDCK-SIAT1 cells, also provided by CDC. Note, an updated CDC reference virus panel version 2, for NAI susceptibility testing, was introduced in October, 2012 (season 2012-13), and comprises viruses different from those in the 2011-2012 panel, with exception of A/Washington/01/ 2007(H3N2) wildtype, A/Texas/12/2007(H3N2) NA-E119V, B/ Memphis/20/96 wildtype and B/Memphis/20/96 NA-R152K (Supplementary Table S1). Laboratories conducting influenza virological surveillance using NI assays can obtain this panel from the Influenza Reagent Resource (IRR) upon registration and approval (Catalogue No. FR-1176) (http:// www.influenzareagentresource.org/Catalog.aspx).

\subsection{Neuraminidase inhibitors}

Oseltamivir carboxylate, the active compound of the ethyl ester prodrug oseltamivir phosphate was kindly provided by HoffmannLa Roche (Basel, Switzerland), zanamivir by GlaxoSmithKline (Uxbridge, UK), and peramivir by BioCryst Pharmaceuticals 
Table 1

Fluorescent NI assay $\mathrm{IC}_{50} \mathrm{~s}$ for the 2011-12 CDC reference virus panel, tested by CDC.

\begin{tabular}{|c|c|c|c|c|}
\hline \multirow[t]{2}{*}{ Virus name } & \multirow[t]{2}{*}{ Influenza type/subtype } & \multicolumn{3}{|l|}{ Mean $\mathrm{IC}_{50} \pm \mathrm{SD}^{\mathrm{a}}[\text { Range }]^{\mathrm{b}}(\mathrm{nM})$} \\
\hline & & Oseltamivir & Zanamivir & Peramivir \\
\hline A/California/07/2009 Wildtype & A(H1N1)pdm09 & $0.21 \pm 0.02[0.19-0.23]$ & $0.20 \pm 0.01[0.19-0.21]$ & $0.05 \pm 0.05[0.05-0.05]$ \\
\hline A/North Carolina/39/2009 H275Y & A(H1N1)pdm09 & $151.13 \pm 12.08[140.04-164.00]$ & $0.22 \pm 0.01[0.21-0.22]$ & $17.75 \pm 0.66[17.03-18.33]$ \\
\hline A/Washington/10/2008 Wildtype & $\mathrm{A}(\mathrm{H} 1 \mathrm{~N} 1)$ & $0.59 \pm 0.08[0.50-0.65]$ & $0.25 \pm 0.05[0.21-0.30]$ & $0.07 \pm 0.01[0.06-0.08]$ \\
\hline A/Florida/21/2008 H275Y & $\mathrm{A}(\mathrm{H} 1 \mathrm{~N} 1)$ & $562.97 \pm 55.49[504.00-614.15]$ & $0.52 \pm 0.08[0.43-0.58]$ & $73.48 \pm 10.61[61.63-82.11]$ \\
\hline A/Washington/01/2007 Wildtype & $\mathrm{A}(\mathrm{H} 3 \mathrm{~N} 2)$ & $0.06 \pm 0.01[0.05-0.07]$ & $0.69 \pm 0.14[0.55-0.82]$ & $0.08 \pm 0.01[0.07-0.09]$ \\
\hline A/Texas/12/2007 E119V & $\mathrm{A}(\mathrm{H} 3 \mathrm{~N} 2)$ & $45.36 \pm 7.30[40.42-53.75]$ & $0.46 \pm 0.05[0.43-0.51]$ & $0.10 \pm 0.09[0.09-0.11]$ \\
\hline B/Memphis/20/1996 Wildtype & $\mathrm{B}$ & $4.45 \pm 0.19[4.28-4.65]$ & $1.19 \pm 0.04[1.16-1.24]$ & $0.30 \pm 0.02[0.29-0.32]$ \\
\hline B/Memphis/20/1996 R152K & $\mathrm{B}$ & $600.38 \pm 84.81[523.81-690.89]$ & $62.60 \pm 5.18[56.87-66.96]$ & $278.22 \pm 21.16$ [254.17-293.99] \\
\hline
\end{tabular}

Abbreviations - SD: Standard deviation.

a Three independent NI assays.

b Range: minimum to maximum $\mathrm{IC}_{50}$.

(Birmingham, AL). Note, oseltamivir, zanamivir and peramivir are also available commercially (Sequoia Research Products, Pangbourne, United Kingdom). In this study, NAIs (in powder form) were obtained from respective manufacturers through material transfer agreements (MTAs), then weighed and reconstituted using deionized distilled water (to $20 \mathrm{mM}$ solutions), according to procedures described in the CDC fluorescent NI assay protocol. These $20 \mathrm{mM}$ solutions were then diluted into $50 \mu \mathrm{M}$ stock solutions, which were used to prepare 3.16 -fold (half- $\log _{10}$ ) serial dilutions of NAIs (total of 10), starting from $4 \mu \mathrm{M}(4000 \mathrm{nM})$ to a final concentration of $0.12 \mathrm{nM}$.

\subsection{Neuraminidase inhibition assay}

Virus susceptibility to NAIs was assessed in the fluorescent NI assay that utilizes 2-(4-methylumbelliferyl)-a-D-N-acetylneuraminic acid (MUNANA) as substrate. The assay was performed using the NA-Fluor ${ }^{\mathrm{TM}}$ Influenza Neuraminidase Assay Kit (Applied Biosystems/Life Technologies, Carlsbad, CA) in 96-well opaque black flat-bottom microplates (Corning Inc., Corning, NY), according to the $\mathrm{CDC}$ protocol, which can be requested by email (fluantiviral@cdc.gov). The CDC fluorescent NI assay protocol is optimized to the needs of virological surveillance (OkomoAdhiambo et al., 2013) and somewhat differs from the manufacturer's instructions in the NA-Fluor ${ }^{\mathrm{TM}}$ kit manual. Briefly, viruses were diluted at concentrations corresponding to the target fluorescence signal generated by 1000 pmol/well of 4methylumbelliferone (4-MU) standard. A virus dilution calculation spreadsheet (Excel, Microsoft, Redmond, WA) was used to determine the appropriate dilution of virus to be used in the inhibition portion of the assay. This tool rapidly provides the dilutions of virus, together with the volumes of virus and $1 \times$ NA-Fluor ${ }^{\mathrm{TM}}$ Assay Buffer to be used. Subsequently, $25 \mu \mathrm{L}$ of each diluted virus was mixed with $25 \mu \mathrm{L}$ of a range of concentrations of each NAI (0.12 nM-4000 nM; with a final concentration in the reaction of $0.03 \mathrm{nM}-1000 \mathrm{nM}$ ) and incubated at $37^{\circ} \mathrm{C}$ for $45 \mathrm{~min}$, after which $50 \mu \mathrm{L}$ of the $200 \mu \mathrm{M}$ NA-Fluor ${ }^{\mathrm{TM}}$ Substrate (MUNANA) was added to the virus and inhibitor mix, and incubated at $37^{\circ} \mathrm{C}$ for $60 \mathrm{~min}$. The reaction was terminated with $100 \mu \mathrm{L}$ NA-Fluor ${ }^{\mathrm{TM}}$ Stop Solution. Fluorescence was detected on the Victor ${ }^{3} \mathrm{~V}^{\mathrm{TM}}$ (USLPH), Victor X4 ${ }^{\mathrm{TM}}$ (WSLH) or Victor X2 ${ }^{\mathrm{TM}}(\mathrm{CDPH})$ plate reader (PerkinElmer, Shelton, $\mathrm{CT})$, equipped with filters for excitation $(\lambda=365 \mathrm{~nm})$ and emission $(\lambda=450 \mathrm{~nm})$. Note, the CDC currently uses the BioTek ${ }^{\mathrm{TM}}$ plate reader platform, models Synergy $\mathrm{H}^{\mathrm{TM}}{ }^{\mathrm{TM}}$, Synergy $\mathrm{Neo}^{\mathrm{TM}}$ and Cytation $3^{\text {TM }}$ (BioTek Instruments Inc., Winooski, VT).

\subsection{Resources provided by $C D C$}

Participating laboratories (NSRC-Is) were provided with a detailed standard operating procedure (SOP) for the fluorescent NI assay utilizing the NA-Fluor ${ }^{\mathrm{TM}}$ Influenza Neuraminidase Assay Kit (Okomo-Adhiambo et al., 2013). Besides the SOP, the CDC also provided materials and tools, including a virus dilution calculator tool; JASPR v1.2 curve-fitting software (CDC, Atlanta, GA); the 2011-12 CDC reference virus panel; aliquots of verified $50 \mu \mathrm{M}$ NAI stock solutions (for the first phase of the study); and technical support for troubleshooting. Additionally, CDC laboratorians conducted site visits to monitor NI assay implementation for the impending 2011-12 influenza season.

\subsection{Testing algorithm for NI assay standardization}

In the first phase of the standardization process, participating laboratories (NSRC-Is) performed the NI assay on 2011-12 CDC reference panel viruses grown by $\operatorname{CDC}(n=8)$, using NAIs that the CDC obtained, weighed, reconstituted and diluted. The laboratories were provided with $50 \mu \mathrm{M}$ NAI stock solutions which they diluted to the final concentrations $(0.12-4000 \mathrm{nM})$ required for $\mathrm{NI}$ assay testing. For the second phase, participating laboratories prepared their own stocks of the 2011-12 CDC reference panel viruses, and tested them with NAIs they obtained from manufacturers in powder form, and weighed, reconstituted and diluted in-house. Commonly, each NI assay test was replicated at least twice. After successfully completing the NI assay standardization process, the NSRC-Is tested U.S. influenza A and B surveillance isolates collected during the 2011-12 season $(\mathrm{n}=940)$, using NAIs obtained and prepared in-house. A subset $(n=742)$ of these viruses were tested in parallel by the CDC. The 2011-12 CDC reference panel influenza A(H1N1)pdm09 viruses, A/California/07/2009 wildtype and A/ North Carolina/39/2009 H257Y, were included in each NI assay test as controls. Note, the tested surveillance isolates were propagated by NSRC-Is as part of the VI/NI project or by CDC (viruses submitted to CDC directly), and NAIs were prepared by each NSRC-I and the CDC, respectively. Subsequently, the NSRC-Is tested surveillance isolates $(\mathrm{n}=6773$ ) circulating during the 2012-15 influenza seasons; the $\mathrm{A}(\mathrm{H} 1 \mathrm{~N} 1) \mathrm{pdm} 09$ viruses, $\mathrm{A} /$ California/12/2012 wildtype and $\mathrm{A} /$ Texas/23/2012 H275Y, from CDC reference virus panel version 2 , were included in each NI assay test for quality control. All NI assay data generated by the NSRC-Is were submitted to the CDC for evaluation via secure file transfer protocol (FTP).

\subsection{Data analysis}

Fifty percent inhibitory concentration $\left(\mathrm{IC}_{50}\right)$ values were determined using JASPR v1.2 curve-fitting software (CDC, Atlanta, GA) by participating laboratories. The CDC laboratory performed statistical analyses of $\mathrm{IC}_{50}$ values using SAS v9.3 (SAS Institute, Cary, NC), with statistical significance set at $\alpha=0.05$. One-way analysis of variance 
(ANOVA) was used to compare means of $\mathrm{IC}_{50}$ s generated for the 2011-12 reference virus panel tested for the standardization process, while non-parametric ANOVA (Pappas and DePuy, 2004) was used to compare medians of $\mathrm{IC}_{50}$ s for the 2011-15 U.S. surveillance isolates.

\subsection{Sequence analysis}

To identify known and/or novel markers associated with elevated $\mathrm{IC}_{50}$, viral RNA was extracted from isolates and NA sequence analyzed by pyrosequencing (Deyde and Gubareva, 2009) and/or Sanger sequencing (Sheu et al., 2008). Amino acid substitutions are named according to specific influenza A NA subtype or B type sequence numbering (straight numbering).

\section{Results}

The NI assay standardization process was conducted on the 2011-12 CDC reference virus panel (Table 1) comprising four pairs of wildtype virus and NA variants with known molecular markers previously associated with elevated $\mathrm{IC}_{50} \mathrm{~s}$ for one or more NAIs, covering a wide range of $\mathrm{IC}_{50}$ values. The three participating laboratories designated as NSRC-Is (CDPH, USLPH, and WSLH), first tested the 2011-12 CDC reference virus panel propagated by CDC, using NAIs obtained and prepared by the CDC (the laboratories were provided with $50 \mu \mathrm{M}$ stock solutions which they diluted further). This was followed by testing of the same reference virus panel propagated by each participating laboratory, and using NAIs they obtained and prepared in-house (Table 2).

The $\mathrm{IC}_{50} \mathrm{~S}$ generated for $\mathrm{CDC}$-propagated viruses with $\mathrm{CDC}$ - prepared NAIs (Table 2) were similar and exhibited minimal inter-assay variation within respective laboratories. There was minimal inter-laboratory variation in $\mathrm{IC}_{50} \mathrm{~S}$, which, with few exceptions, was statistically insignificant. For example, the zanamivir $\mathrm{IC}_{50}$ for A/Washington/10/2008(H1N1) wildtype virus generated by WSLH (0.32 nM) was 2-fold greater than that for CDPH (0.16 nM), while zanamivir $\mathrm{IC}_{50}$ for B/Memphis/20/1996 R152K variant virus generated by CDPH (67.94 nM) was 2-fold more than for USLPH $(33.13 \mathrm{nM})$ and WSLH $(43.20 \mathrm{nM})$. Similarly, the peramivir $\mathrm{IC}_{50}$ for A/Washington/01/2007(H3N2) wildtype virus generated by WSLH $(0.14 \mathrm{nM})$ was 2-3-fold higher compared to those of CDPH $(0.06 \mathrm{nM})$ and USLPH $(0.05 \mathrm{nM})$. These differences were not statistically significant $(\mathrm{p}>0.05)$.

Using viruses they propagated and NAIs prepared in-house, the participating laboratories were able to successfully reproduce the $\mathrm{IC}_{50} \mathrm{~S}$ they generated using the viruses and NAIs prepared by the CDC ( $p$-values comparing $\mathrm{IC}_{50}$ s derived from the two scenarios were insignificant, range $0.073-0.980$ ). These $\mathrm{IC}_{50} \mathrm{~S}$ also exhibited minimal inter-assay and inter-laboratory variation, although those generated by USLPH tended to be lower ( $\leq 2$-fold) compared to those of CDPH and WSLH. However, these differences were generally $<2$-fold and were not significant at the assessed level of confidence ( $\mathrm{p}>0.05$ ). Overall, the $\mathrm{IC}_{50}$ s for the 2011-12 reference virus panel generated by the three laboratories for the standardization process, were comparable to those generated by the $\mathrm{CDC}$ for the same reference virus panel (Table 1), and were within the ranges expected for wildtype and NA variant virus pairs of the four influenza type/subtypes that were assessed.

Upon completion of testing the 2011-12 CDC reference virus panel for the standardization process, and implementing the $\mathrm{NI}$

Table 2

Fluorescent NI assay $\mathrm{IC}_{50}$ s for the 2011-12 CDC reference virus panel, tested by three NSRC-Is (CDPH, USLPH and WSLH) for the standardization process.

\begin{tabular}{|c|c|c|c|c|c|c|c|c|}
\hline \multirow[t]{3}{*}{ NAI } & \multirow[t]{3}{*}{ Virus name } & \multirow[t]{3}{*}{ Influenza type/Subtype } & \multicolumn{6}{|c|}{ Mean $\mathrm{IC}_{50} \pm \mathrm{SD}(\mathrm{nM})$} \\
\hline & & & \multicolumn{3}{|c|}{ CDC Drug/Virus ${ }^{a, \dagger}$} & \multicolumn{3}{|c|}{ PHL Drug/Virus ${ }^{\mathrm{b}, \dagger}$} \\
\hline & & & $\mathrm{CDPH}$ & USLPH & WSLH & $\mathrm{CDPH}^{\mathrm{c}}$ & USLPH & WSLH \\
\hline \multirow[t]{8}{*}{ Oseltamivir } & A/California/07/2009 Wildtype & A(H1N1)pdm09 & $0.15 \pm 0.06$ & $0.16 \pm 0.11$ & $0.11 \pm 0.02$ & 0.09 & $0.12 \pm 0.03$ & $0.18 \pm 0.06$ \\
\hline & A/North Carolina/39/2009 H275Y & $\mathrm{A}(\mathrm{H} 1 \mathrm{~N} 1) \mathrm{pdm} 09$ & $140.44 \pm 15.58$ & $120.58 \pm 36.71$ & $135.39 \pm 15.85$ & 128.76 & $117.02 \pm 21.62$ & $146.64 \pm 16.7$ \\
\hline & A/Washington/10/2008 Wildtype & $\mathrm{A}(\mathrm{H} 1 \mathrm{~N} 1)$ & $0.38 \pm 0.08$ & $0.42 \pm 0.27$ & $0.34 \pm 0.06$ & 0.36 & $0.33 \pm 0.08$ & $0.96 \pm 0.97$ \\
\hline & A/Florida/21/2008 H275Y & $\mathrm{A}(\mathrm{H} 1 \mathrm{~N} 1)$ & $431.27 \pm 44.64$ & $319.71 \pm 124.5$ & $404.18 \pm 19.11$ & 399.73 & $234.54 \pm 33.06$ & $452.63 \pm 79.77$ \\
\hline & A/Washington/01/2007 Wildtype & $\mathrm{A}(\mathrm{H} 3 \mathrm{~N} 2)$ & $0.05 \pm 0.01$ & $0.04 \pm 0.01$ & $0.04 \pm 0.01$ & 0.04 & $0.04 \pm 0.00$ & $0.04 \pm 0.01$ \\
\hline & A/Texas/12/2007 E119V & $\mathrm{A}(\mathrm{H} 3 \mathrm{~N} 2)$ & $34.21 \pm 0.62$ & $33.53 \pm 12.75$ & $28.48 \pm 5.23$ & 33.01 & $27.45 \pm 6.26$ & $39.76 \pm 17.68$ \\
\hline & B/Memphis/20/1996 Wildtype & B & $3.88 \pm 1.03$ & $3.11 \pm 1.93$ & $2.72 \pm 0.56$ & 2.46 & $2.40 \pm 0.51$ & $3.30 \pm 1.79$ \\
\hline & B/Memphis/20/1996 R152K & B & $472.84 \pm 47.23$ & $421.62 \pm 120.11$ & $410.49 \pm 48.62$ & 469.35 & $311.30 \pm 37.50$ & $473.88 \pm 37.41$ \\
\hline \multirow[t]{8}{*}{ Zanamivir } & A/California/07/2009 Wildtype & A(H1N1)pdm09 & $0.15 \pm 0.02$ & $0.16 \pm 0.05$ & $0.14 \pm 0.03$ & 0.13 & $0.16 \pm 0.03$ & $-{ }^{\mathrm{d}}$ \\
\hline & A/North Carolina/39/2009 H275Y & $\mathrm{A}(\mathrm{H} 1 \mathrm{~N} 1) \mathrm{pdm} 09$ & $0.14 \pm 0.01$ & $0.17 \pm 0.06$ & $0.16 \pm 0.03$ & 0.12 & $0.20 \pm 0.01$ & - \\
\hline & A/Washington/10/2008 Wildtype & $\mathrm{A}(\mathrm{H} 1 \mathrm{~N} 1)$ & $0.16 \pm 0.01$ & $0.23 \pm 0.09$ & $0.32 \pm 0.12$ & 0.17 & $0.23 \pm 0.01$ & - \\
\hline & A/Florida/21/2008 H275Y & $\mathrm{A}(\mathrm{H} 1 \mathrm{~N} 1)$ & $0.52 \pm 0.09$ & $0.61 \pm 0.37$ & $0.76 \pm 0.21$ & 0.45 & $0.54 \pm 0.06$ & - \\
\hline & A/Washington/01/2007 Wildtype & $\mathrm{A}(\mathrm{H} 3 \mathrm{~N} 2)$ & $0.76 \pm 0.35$ & $0.75 \pm 0.48$ & $0.60 \pm 0.26$ & 0.52 & $0.93 \pm 0.47$ & - \\
\hline & A/Texas/12/2007 E119V & $\mathrm{A}(\mathrm{H} 3 \mathrm{~N} 2)$ & $0.26 \pm 0.08$ & $0.35 \pm 0.12$ & $0.34 \pm 0.07$ & 0.25 & $0.38 \pm 0.01$ & - \\
\hline & B/Memphis/20/1996 Wildtype & B & $0.71 \pm 0.21$ & $0.81 \pm 0.35$ & $0.74 \pm 0.09$ & 0.59 & $0.76 \pm 0.09$ & - \\
\hline & B/Memphis/20/1996 R152K & B & $67.94 \pm 2.20$ & $33.13 \pm 24.59$ & $43.20 \pm 12.21$ & 49.90 & $23.73 \pm 4.45$ & - \\
\hline \multirow[t]{8}{*}{ Peramivir } & A/California/07/2009 Wildtype & A(H1N1)pdm09 & $0.04 \pm 0.01$ & $0.04 \pm 0.01$ & $0.03 \pm 0.01$ & 0.04 & $0.05 \pm 0.01$ & $0.02 \pm 0.01$ \\
\hline & A/North Carolina/39/2009 H275Y & A(H1N1)pdm09 & $14.97 \pm 0.40$ & $15.63 \pm 3.94$ & $13.98 \pm 2.66$ & 18.97 & $17.45 \pm 1.89$ & $14.45 \pm 1.4$ \\
\hline & A/Washington/10/2008 Wildtype & $\mathrm{A}(\mathrm{H} 1 \mathrm{~N} 1)$ & $0.04 \pm 0.01$ & $0.05 \pm 0.02$ & $0.04 \pm 0.01$ & 0.05 & $0.07 \pm 0.02$ & $0.06 \pm 0.03$ \\
\hline & A/Florida/21/2008 H275Y & $\mathrm{A}(\mathrm{H} 1 \mathrm{~N} 1)$ & $65.60 \pm 0.00$ & $67.89 \pm 11.48$ & $64.32 \pm 11.59$ & 71.17 & $68.14 \pm 6.59$ & $67.61 \pm 14.61$ \\
\hline & A/Washington/01/2007 Wildtype & $\mathrm{A}(\mathrm{H} 3 \mathrm{~N} 2)$ & $0.06 \pm 0.01$ & $0.05 \pm 0.02$ & $0.14 \pm 0.10$ & 0.06 & $0.07 \pm 0.02$ & $0.05 \pm 0.01$ \\
\hline & A/Texas/12/2007 E119V & $\mathrm{A}(\mathrm{H} 3 \mathrm{~N} 2)$ & $0.08 \pm 0.02$ & $0.08 \pm 0.02$ & $0.06 \pm 0.02$ & 0.09 & $0.10 \pm 0.03$ & $0.06 \pm 0.02$ \\
\hline & B/Memphis/20/1996 Wildtype & B & $0.23 \pm 0.09$ & $0.24 \pm 0.06$ & $0.20 \pm 0.04$ & 0.26 & $0.35 \pm 0.13$ & $0.18 \pm 0.02$ \\
\hline & B/Memphis/20/1996 R152K & B & $256.27 \pm 32.63$ & $215.92 \pm 35.38$ & $208.57 \pm 52.42$ & 245.65 & $229.11 \pm 43.03$ & $244.9 \pm 78.28$ \\
\hline
\end{tabular}


State Laboratory of Hygiene. SD: standard deviation.

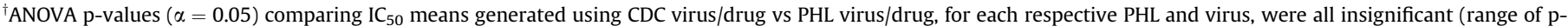
values $0.073-0.980)$.

a CDC-propagated virus tested with CDC-reconstituted drug (PHLs diluted provided $50 \mu \mathrm{M}$ solutions). Assay replicated twice.

b PHL-propagated virus tested with PHL-reconstituted/diluted drug. Assay replicated twice, with exceptions.

c Assay performed only once.

d Zanamivir not available for testing. 
assay, the three NSRC-Is (CDPH, USLPH and WSLH) performed the NI assay on 2011-12 U.S. influenza surveillance specimens (Table 3), in efforts to strengthen domestic influenza virological surveillance. A total of 940 virus isolates were tested by the NSRCIs, of which $742(80 \%)$ were tested in parallel by CDC for data quality purposes, and to enable testing of virus susceptibility to investigational laninamivir (data not shown). Within individual laboratories, there was minimal inter-assay variation in $\mathrm{IC}_{50} \mathrm{~S}$ for the respective NAIs and virus type/subtypes (Table 3 ). Inter-laboratory variation in $\mathrm{IC}_{50} \mathrm{~S}$ was also minimal, with few exceptions that were not statistically significant $(\mathrm{p}>0.05)$. For example, the mean oseltamivir $\mathrm{IC}_{50}$ for $\mathrm{A}(\mathrm{H} 1 \mathrm{~N} 1)$ pdm09 viruses generated by WSLH (0.12 nM) was $\sim 2$-fold lower than that for CDPH (0.19 nM) and only slightly less than for USLPH $(0.16 \mathrm{nM})$. Similarly, the mean peramivir $\mathrm{IC}_{50}$ for B viruses generated by WSLH $(0.27 \mathrm{nM})$ was $\sim 2$-fold lower than those for CDPH (0.49 nM) and USLPH (0.54 nM). Overall, the $\mathrm{IC}_{50} \mathrm{~s}$ for respective NAIs and virus type/subtypes generated by the NSRC-Is, were consistent and comparable with those generated by the CDC for the same set of viruses (Table 3).

As outlined in the CDC SOP for the fluorescent NI assay, the pair of $\mathrm{A}(\mathrm{H} 1 \mathrm{~N} 1)$ pdm09 viruses, $\mathrm{A} /$ California/07/2009 wildtype and $\mathrm{A} /$ North Carolina/39/2009 NA-H275Y, from the 2011-12 CDC reference panel, were propagated by NSRC-Is to prepare sizeable stocks to enable aliquots of these viruses to be included in each NI assay test for quality control purposes. Note, in October 2012, these viruses were replaced by the $\mathrm{A}(\mathrm{H} 1 \mathrm{~N} 1) \mathrm{pdm} 09$ virus pair, A/California/ $12 / 2012$ wildtype and A/Texas/23/2012 H275Y, that are in the current CDC reference virus panel version 2.

Following successful NI assay testing in season 2011-12, the three NSRC-Is continued testing U.S. surveillance isolates ( $\mathrm{n}=6773$ ) circulating during the 2012-13 ( $\mathrm{n}=2114), 2013-14$ $(\mathrm{n}=2756)$ and $2014-15(\mathrm{n}=1903)$ influenza seasons. During these three seasons, as well as the previous 2011-12 season, the NSRC-Is assessed virus susceptibility to three NAIs, oseltamivir, zanamivir and peramivir, but in 2012-13 they did not monitor peramivir susceptibility. Median $\mathrm{IC}_{50}$ S for oseltamivir, zanamivir and peramivir generated by the NSRC-Is during four influenza seasons (2011-15) were generally uniform within individual laboratories from season to season (Fig. 1), although a few exceptions were noted. Within WSLH, the median $\mathrm{IC}_{50}$ for peramivir among influenza $\mathrm{A}(\mathrm{H} 1 \mathrm{~N} 1)$ pdm09 viruses in 2011-12 (0.03 nM) was $~ 2$-fold lower compared to seasons 2013-14 (0.05 nM) and 2014-15
(0.06 nM). Among the NSRC-Is, median $\mathrm{IC}_{50}$ s for respective NAIs and virus type/subtypes were consistent during 2011-2015, with few exceptions, such as the 2014-15 median IC $_{50}$ of oseltamivir among influenza B generated by CDPH (10.54 nM), which varied by almost 2-fold compared to USLPH (4.99 $\mathrm{nM}$ ) and was slightly higher than that for WSLH $(7.15 \mathrm{nM})$. Overall, the median $\mathrm{IC}_{50} \mathrm{~S}$ obtained by the NSRC-Is over four seasons (2011-15), for respective NAIs and virus type/subtypes, were consistent with those generated by CDC (Supplemental Table S2), and differences if any were $\leq 2$-fold and not statistically significant $(\mathrm{p}<0.05)$.

The standardization process significantly increased capabilities for the NI assay in the U.S., with NSRC-Is accounting for $~ 80 \%$ of all $\mathrm{NI}$ testing performed on U.S. surveillance isolates circulating during the 2012-13, 2013-14 and 2014-15 influenza seasons. Standardizing the NI assay is, however, not practical for laboratories involved in monitoring influenza antiviral susceptibility globally. To address this issue, WHO-AVWG developed a set of criteria for reporting NI assay results based on $\mathrm{IC}_{50}$ fold change difference compared to a reference such as the median $\mathrm{IC}_{50}$ for the respective NAI and virus type (WHO, 2012). During seasons 2012-15, these criteria were applied to identify viruses with fold differences above a respective median $\mathrm{IC}_{50}$ value for the same NAI and type/subtype; viruses exhibiting RI or HRI were re-tested in the NI assay by NSRC-Is for the result confirmation and submitted to $\mathrm{CDC}$ for comprehensive characterization. In some instances, epidemiological investigations were initiated by the CDC (Okomo-Adhiambo et al., 2015; Garg et al., 2013).

The introduction of the WHO-AVWG criteria (WHO, 2012) allowed an expanded scope of the original project. Two state PHLs that were not part of the primary CDC/APHL standardization project, MD DHMH, and the New York State Department of Health (NYDOH), also conducted NI testing using the NA-Fluor ${ }^{\mathrm{TM}}$ Influenza Neuraminidase Assay Kit, according to their in-house protocols. The generated $\mathrm{IC}_{50}$ values were interpreted in accord with the WHOAVWG classification criteria. During the 2014-15 season, the MD DHMH laboratory tested a total of 329 influenza A(H3N2) $(n=253)$ and $B(n=76)$ viruses collected in the state of Maryland between Oct 01, 2014 and May 17, 2015. All viruses exhibited normal inhibition by oseltamivir, zanamivir and peramivir, with exception of one $(0.4 \%) \mathrm{A}(\mathrm{H} 3 \mathrm{~N} 2)$ virus with RI by zanamivir (15-fold increase in $\mathrm{IC}_{50}$ compared to the median $\mathrm{IC}_{50}$ for the subtype). This virus and its original clinical specimen were submitted to $\mathrm{CDC}$ for further

Table 3

Fluorescent NI assay $\mathrm{IC}_{50}$ s for season 2011-12 U.S. influenza A and B surveillance isolates, tested in parallel by the NSRC-Is and CDC ( $\mathrm{n}=742$ ).

\begin{tabular}{|c|c|c|c|c|c|c|}
\hline \multirow[t]{2}{*}{ NAI } & \multirow[t]{2}{*}{ Influenza type/Subtype } & \multicolumn{4}{|c|}{ Mean $\mathrm{IC}_{50} \pm \mathrm{SD}[\text { Range }]^{\mathrm{a}}(\mathrm{nM})$} & \multirow[t]{2}{*}{$r^{\mathrm{f}}$} \\
\hline & & $\mathrm{CDPH}(\mathrm{n}=251)$ & USLPH $(\mathrm{n}=248)$ & WSLH $(\mathrm{n}=243)$ & $\operatorname{CDC}(\mathrm{n}=742)$ & \\
\hline \multirow[t]{3}{*}{ Oseltamivir } & A(H1N1)pdm09 & $0.19 \pm 0.06[0.06-0.38]^{b}$ & $0.16 \pm 0.04[0.10-0.27]^{\mathrm{c}}$ & $0.12 \pm 0.02[0.07-0.15]^{\mathrm{d}}$ & $0.20 \pm 0.05[0.11-0.49]^{b, c, d}$ & 0.978 \\
\hline & $\mathrm{A}(\mathrm{H} 3 \mathrm{~N} 2)$ & $0.10 \pm 0.04[0.02-0.40]$ & $0.11 \pm 0.02[0.07-0.20]$ & $0.07 \pm 0.03[0.04-0.26]$ & $0.12 \pm 0.05[0.04-0.53]$ & 0.714 \\
\hline & $\mathrm{B}^{\mathrm{h}}$ & $8.04 \pm 2.42[0.68-12.77]^{\mathrm{e}}$ & $7.57 \pm 2.04[4.91-14.49]$ & $5.45 \pm 1.97[0.10-14.00]$ & $8.09 \pm 2.92[0.11-16.19]^{e}$ & 0.836 \\
\hline \multirow[t]{3}{*}{ Zanamivir } & A(H1N1)pdm09 & $0.11 \pm 0.02[0.08-0.18]^{\mathrm{b}}$ & $0.16 \pm 0.03[0.10-0.35]^{c}$ & $-g$ & $0.18 \pm 0.04[0.12-0.37]^{b, c, d}$ & 0.477 \\
\hline & $\mathrm{A}(\mathrm{H} 3 \mathrm{~N} 2)$ & $0.18 \pm 0.09[0.09-0.64]$ & $0.24 \pm 0.05[0.13-0.40]$ & - & $0.28 \pm 0.11[0.12-0.98]$ & 0.491 \\
\hline & $\mathrm{B}^{\mathrm{h}}$ & $0.79 \pm 0.29[0.30-1.25]$ & $1.11 \pm 0.31[0.67-1.70]$ & - & $1.29 \pm 0.59[0.49-2.38]^{\mathrm{e}}$ & 0.572 \\
\hline \multirow[t]{3}{*}{ Peramivir } & A(H1N1)pdm09 & $0.05 \pm 0.01[0.03-15.47]^{\mathrm{b}}$ & $0.06 \pm 0.01[0.04-0.09]^{c}$ & $0.03 \pm 0.01[0.02-0.08]^{\mathrm{d}}$ & $0.05 \pm 0.01[0.03-0.11]^{b, c, d}$ & 0.989 \\
\hline & $\mathrm{A}(\mathrm{H} 3 \mathrm{~N} 2)$ & $0.07 \pm 0.01[0.04-0.13]$ & $0.09 \pm 0.02[0.06-0.16]$ & $0.06 \pm 0.02[0.04-0.25]$ & $0.09 \pm 0.02[0.04-0.35]$ & 0.265 \\
\hline & $\mathrm{B}^{\mathrm{h}}$ & $0.49 \pm 0.21[0.24-1.48]^{\mathrm{e}}$ & $0.54 \pm 0.12[0.32-0.90]$ & $0.27 \pm 0.07[0.07-0.54]$ & $0.42 \pm 0.15[0.08-1.10]^{\mathrm{e}}$ & 0.786 \\
\hline
\end{tabular}


standard deviation.

a Range: minimum to maximum $\mathrm{IC}_{50}$.

b Excludes A/Texas/24/2012 H275Y variant (Ose = $122.88 \mathrm{nM}$; Zan = $0.12 \mathrm{nM}$; Per = $15.47 \mathrm{nM})$.

c Excludes A/Illinois/01/2012 H275Y variant (Ose = $132.67 \mathrm{nM}$; Zan = 0.21 nM; Per = $17.80 \mathrm{nM}$ ).

d Excludes A/Delaware/03/2012 H275Y variant (Ose = 35.71 nM; Per = 3.18 nM).

e Excludes B/California/03/2012 A200 A/T variant (Ose IC $50=30.39$ nM; Zan IC $50=2.11 \mathrm{nM}$; Per IC $50=2.39$ ).

${ }^{f}$ Pearson correlation coefficient between $\mathrm{IC}_{50}$ s generated by PHLs and $\mathrm{CDC}$ for the same viruses.

g Zanamivir was not available for testing.

$\mathrm{h}$ There were no significant differences in $\mathrm{IC}_{50}$ s between type B virus lineages. 

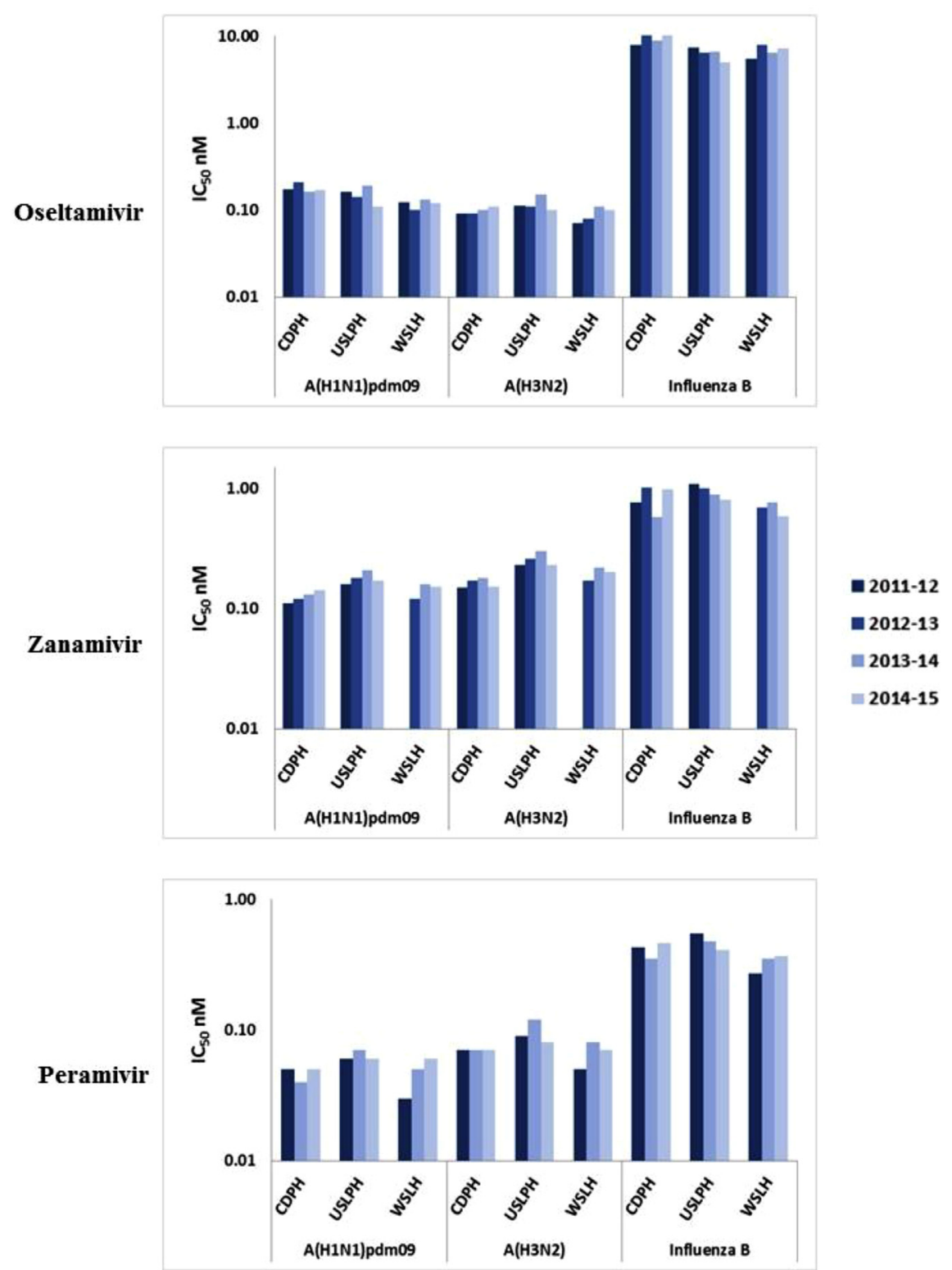

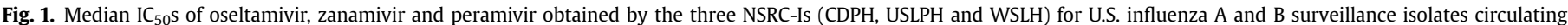

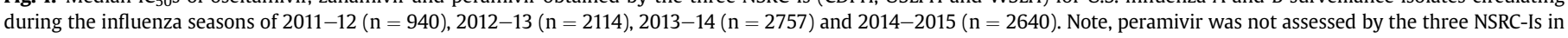
season 2012-13.

characterization. Full NA sequence analysis of the virus isolate detected the cell culture adaptive Q136K substitution, which was absent in the matching clinical specimen. The NYDOH laboratory tested a total of 95 influenza $\mathrm{A}(\mathrm{H} 3 \mathrm{~N} 2)(\mathrm{n}=78)$ and $\mathrm{B}(\mathrm{n}=17)$ viruses collected in New York state between Jan 16 and May 01, 2015; all viruses exhibited normal inhibition by oseltamivir and zanamivir (peramivir was not assessed).

Overall, standardized NI assay procedure with three FDAapproved NAIs, conducted by four laboratories (CDC and three NSRC-Is) ( $\mathrm{n}=3015)$, as well as harmonization of reporting from two additional laboratories (MD DHMH and NYDOH) $(\mathrm{n}=424)$, resulted in a total of 3439 circulating U.S. influenza viruses tested during the 2014-15 season (Oct 01, 2014 to Jun 23, 2015), including $68 \mathrm{~A}(\mathrm{H} 1 \mathrm{~N} 1)$ pdm09, $2174 \mathrm{~A}(\mathrm{H} 3 \mathrm{~N} 2)$ and $1197 \mathrm{~B}$ viruses. Only two $(0.1 \%)$ U.S. viruses with molecular markers of NAI resistance were detected, including one $\mathrm{A}(\mathrm{H} 1 \mathrm{~N} 1)$ pdm09 virus with $\mathrm{H} 275 \mathrm{Y}$ and one A(H3N2) virus with E119V NA substitutions.

\section{Discussion}

Biochemical NI assays have been the cornerstone of NAI susceptibility monitoring programs. They provide a valuable means to screen virus isolates to identify those with elevated $\mathrm{IC}_{50}$ s which can indicate potential NAI resistance. Coupled with genetic analysis, the $\mathrm{NI}$ assay is especially valuable when information on drug resistance markers is not available or sparse, such as when a new NAI is marketed or a novel virus emerges (Sleeman et al., 2013, 2014). The $\mathrm{IC}_{50}$ values generated in NI assays also provide information for comparison of inhibitory effects of different NAIs thus aiding in identification of cross-resistant viruses. Variations in $\mathrm{IC}_{50}$ values determined for the same virus and drug can arise from sources such as use of different enzyme substrates (fluorescent vs chemiluminescent), buffer systems, time of incubation, and other assay conditions (Nguyen et al., 2010; McKimm-Breschkin et al., 2003; McKimm-Breschkin and Barrett, 2014; Tisdale, 2000). 
The goal of the standardization process was to achieve consistency of $\mathrm{IC}_{50}$ data across participating laboratories through the application of uniform NI assay testing procedures (same kit and assay protocol) with support from the CDC reference laboratory. In this study, critical factors including the use of a standardized SOP, commercial NI assay kit, and the CDC reference virus panel, enabled the generation of reproducible results among laboratories participating in the NI assay standardization process. Although participating laboratories and the CDC reference laboratory utilized different plate reader models, all were equipped with standard filters for excitation $(\lambda=365 \mathrm{~nm})$ and emission $(\lambda=450 \mathrm{~nm})$, set to measure fluorescence for $0.1 \mathrm{~s}$. All plate readers were calibrated prior to their initial use by running 4-methylumbelliferone (4-MU) standards to verify optimal plate reader settings and to determine fluorescent signal targeted for virus working dilution. Viruses were diluted at concentrations corresponding to the target fluorescence signal generated by $1000 \mathrm{pmol} /$ well of 4-methylumbelliferone (4MU) standard. This procedure was repeated whenever major repair or recalibration was done to a plate reader. There were no apparent variations in $\mathrm{IC}_{50} \mathrm{~S}$ attributable to differences in plate reader models.

The commercially available NA-Fluor ${ }^{\mathrm{TM}}$ Influenza Neuraminidase Assay Kit used in this study provides the necessary assay reagents, but it lacks NAIs and plates. It also does not include reference material such as influenza viruses exhibiting a range of $\mathrm{IC}_{50}$ values. Preparation of NAI and virus dilutions may vary by laboratory, potentially resulting in $\mathrm{IC}_{50}$ variability. $\mathrm{CDC}$ provided the NAI preparations to see if there were any differences in $\mathrm{IC}_{50} \mathrm{~s}$ for the viruses tested using CDC-prepared drug compared to testing done with NAIs prepared in-house. Preparation of NAIs from their original powder form to concentrations required for the NI assay involves several steps, in which errors may be introduced. In this study, the Tocris Molarity Calculator (http://www.tocris.com/ molarityCalculator.php) was used to determine appropriate volumes of water for initial reconstitution of drugs from powder form. Caution was taken during pipetting to ensure accurate volumes of water were dispensed when diluting NAIs. Laboratories participating in the standardization project were advised to test newly prepared NAIs in parallel to old drug preparations, to confirm accuracy in reconstitution and dilution, and ensure consistency. Although beyond the scope of this study, surveillance laboratories could explore the option of requesting analytically pre-weighed NAIs upon placing a purchase order to commercial entities that offer zanamivir, oseltamivir carboxylate, and peramivir.

In this study, there was no evidence of $\mathrm{IC}_{50}$ variability arising from drug preparation or viruses; differences in $\mathrm{IC}_{50}$ s derived using CDC- versus PHL-prepared drug were minimal ( $<2$-fold) within individual laboratories and also between the laboratories. Two-fold differences in $\mathrm{IC}_{50} \mathrm{~s}$ have been observed among personnel in the same laboratory. The present study also showed no significant variations in $\mathrm{IC}_{50} \mathrm{~S}$ arising from virus propagation. Nevertheless, participating laboratories were advised by the $\mathrm{CDC}$ to limit the number of virus passages since it could lead to emergence of NA changes resulting in elevated $\mathrm{IC}_{50}$ s (Tamura et al., 2013; Mishin et al., 2014).

The success of the NI assay standardization project affirmed that NAI susceptibility data generated in the NI assay could be shared and interpreted in a consistent, reproducible manner. The success of this project can be attributed to several factors including good laboratory practices; the participating laboratories have standard practices of annual pipette calibration, as well as maintenance and performance monitoring of equipment, including plate readers and incubators. The set of tools developed by CDC and shared with the three NSRC-Is, including the fluorescent NI assay SOP, virus dilution calculator, software for $\mathrm{IC}_{50}$ calculation, seeds to propagate in- house reference virus stocks, as well as other support and guidance, were essential for the success of this project. Hands-on training of personnel new to NI testing is also desirable, as is maintaining optimized protocols, as well as necessary reagents, reference viruses and NAI drug stocks. To sustain the quality of future NI assay testing, prior to each upcoming influenza season, laboratories should test reference panels such as CDC or ISIRV-AVG (http://www.isirv.org/site/index.php/reference-panel). Ideally, elements of the NI assay including laboratory infrastructure, protocols, technology, and reagents should be standardized in laboratories in the U.S. and across the globe. However, many laboratories, especially those in resource-poor countries, lack the infrastructure and means necessary to develop, validate, and comply with requirements for NI assay standardization.

The successful implementation of NI testing on season 2011-12 surveillance isolates, and subsequent testing of viruses collected during seasons $2012-15$ by the NSRC-Is, proved the effectiveness of the NI assay standardization and expansion efforts which spanned 5 years, and was instrumental in increasing U.S. domestic influenza antiviral surveillance capabilities and pandemic preparedness. This project marks the first time that $\mathrm{IC}_{50}$ data have been standardized across multiple laboratories performing influenza antiviral susceptibility testing, and incorporated into the U.S. national virological surveillance. The successful NI assay standardization process will enable the expansion of the number of surveillance laboratories capable of drug susceptibility testing both nationally and internationally, assessment of virus susceptibility to new NAIs and testing of novel viruses. These efforts are expected to significantly impact monitoring of influenza antiviral resistance, and will ensure accurate, timely information for public health surveillance.

\section{Disclaimer}

We declare that we have no potential conflicts of interest. The findings and conclusions of this report are those of the authors and do not necessarily represent the views of the Centers for Disease Control and Prevention (CDC).

\section{Acknowledgments}

We wish to acknowledge the CDC Pandemic Influenza Scientific Agenda (PISA) for the partial funding of this initiative. We acknowledge the late Dr. Alexander Klimov, Influenza Division, CDC, for his leadership and support of this project. We acknowledge, our colleagues in the Molecular Epidemiology Team, Virus Reference Team, and Sequencing Activity Team, Virology Surveillance and Diagnosis Branch, Influenza Division, CDC, for their valuable support and contributions to this project. We acknowledge the USLPH, Taylorsville, UT, and the WSLH, Madison, WI, for their participation in this project. We also acknowledge the $\mathrm{CDPH}$, Richmond, CA, for their participation in this project, including the late Dr. David P. Schnurr, Cindy Wong, Nohemi Reyes-Martin, and Debra Wadford for their support. We acknowledge the MD DHMH Laboratories Administration Virus Isolation Team and Fellows for their contributions, including Brittany Wells, for providing the MD DHMH data reported in this manuscript. We acknowledge Pamela Moleta (NTLN/APHL) for her support, and also thank our collaborators in the U.S. public health laboratories for submission of influenza virus isolates and clinical specimens.

\section{Appendix A. Supplementary data}

Supplementary data related to this article can be found at http:// dx.doi.org/10.1016/j.antiviral.2016.01.009. 


\section{References}

CDC Website. Fluview http://www.cdc.gov/flu/weekly/. (accessed 09.10.15.).

Clinical Trials.Gov Website https://clinicaltrials.gov/show/NCT01231620. (accessed 09.10.15.).

Deyde, V.M., Gubareva, L.V., 2009. Influenza genome analysis using pyrosequencing method: current applications for a moving target. Expert Rev. Mol. Diagn. 9 (5), 493-509.

Deyde, V.M., Xu, X., Bright, R.A., Shaw, M., Smith, C.B., Zhang, Y., Shu, Y., Gubareva, L.V., Cox, N.J., Klimov, A.I., 2007. Surveillance of resistance to adamantanes among influenza $\mathrm{A}(\mathrm{H} 3 \mathrm{~N} 2)$ and $\mathrm{A}(\mathrm{H} 1 \mathrm{~N} 1)$ viruses isolated worldwide. J. Infect. Dis. 196 (2), 249-257.

Garg, S., Moore, Z., Lee, N., McKenna, J., Bishop, A., Fleischauer, A., Springs, C.B., Nguyen, H.T., Sheu, T.G., Sleeman, K., Finelli, L., Gubareva, L., Fry, A.M., 2013. A cluster of patients infected with I221V influenza B virus variants with reduced oseltamivir susceptibility-North Carolina and South Carolina, 2010-2011. J. Infect. Dis. 207 (6), 966-973.

IRR Website. http://www.influenzareagentresource.org/Catalog.aspx. (accessed 09.10.15.).

ISIRV Antiviral Group Website. http://www.isirv.org/site/index.php/referencepanel. (accessed 30.11.15.).

McKimm-Breschkin, J., Trivedi, T., Hampson, A., Hay, A., Klimov, A., Tashiro, M., Hayden, F., Zambon, M., 2003. Neuraminidase sequence analysis and susceptibilities of influenza virus clinical isolates to zanamivir and oseltamivir. Antimicrob. Agents Chemother. 47 (7), 2264-2272.

McKimm-Breschkin, J.L., Barrett, S., 2014. Neuraminidase mutations conferring resistance to laninamivir lead to faster drug binding and dissociation. Antivir Res. 114, 62-66.

Meijer, A., Rebelo-de-Andrade, H., Correia, V., Besselaar, T., Drager-Dayal, R., Fry, A. Gregory, V., Gubareva, L., Kageyama, T., Lackenby, A., Lo, J., Odagiri, T. Pereyaslov, D., Siqueira, M.M., Takashita, E., Tashiro, M., Wang, D., Wong, S., Zhang, W. Daniels, R.S., Hurt, A.C., 2014. Global update on the susceptibility of human influenza viruses to neuraminidase inhibitors, 2012-2013. Antivir. Res. 110, 31-41.

Mishin, V.P., Sleeman, K., Levine, M., Carney, P.J., Stevens, J., Gubareva, L.V., 2014. The effect of the MDCK cell selected neuraminidase D151G mutation on the drug susceptibility assessment of influenza A(H3N2) viruses. Antivir. Res. 101, 93-96.

Monto, A.S., McKimm-Breschkin, J.L., Macken, C., Hampson, A.W., Hay, A., Klimov, A Tashiro, M., Webster, R.G., Aymard, M., Hayden, F.G., Zambon, M., 2006. Detection of influenza viruses resistant to neuraminidase inhibitors in global surveillance during the first 3 years of their use. Antimicrob. Agents Chemother. 50 (7), 2395-2402.

Mungall, B.A., Xu, X., Klimov, A., 2004. Surveillance of influenza isolates for susceptibility to neuraminidase inhibitors during the 2000-2002 influenza seasons. Virus Res. 103 (1-2), 195-197.

Nguyen, H.T., Sheu, T.G., Mishin, V.P., Klimov, A.I., Gubareva, L.V., 2010. Assessment of pandemic and seasonal influenza A (H1N1) virus susceptibility to neuraminidase inhibitors in three enzyme activity inhibition assays. Antimicrob. Agents. Chemother. 54 (9), 3671-3677.

Okomo-Adhiambo, M., Fry, A.M., Su, S., Nguyen, H.T., Elal, A.A., Negron, E., Hand, J., Garten, R.J., Barnes, J., Xiyan, X., Villanueva, J.M., Gubareva, L.V., 2013-14 US Influenza Antiviral Working Group., 2015. Oseltamivir-resistant influenza A(H1N1)pdm09 viruses, United States, 2013-14. Emerg. Infect. Dis. 21 (1), $136-141$.

Okomo-Adhiambo, M., Nguyen, H.T., Abd Elal, A., Sleeman, K., Fry, A., Gubareva, L.V., 2014. Drug susceptibility surveillance of influenza viruses circulating in the
United States in 2011-2012: application of WHO antiviral working group criteria. Influenza Other Respir. Viruses 8 (2), 258-265.

Okomo-Adhiambo, M., Sleeman, K., Lysen, C., Nguyen, H.T., Xu, X., Li, Y., Klimov, A.I., Gubareva, L.V., 2013. Neuraminidase inhibitor susceptibility surveillance of influenza viruses circulating worldwide during the 2011 Southern Hemisphere season. Influenza Other Respir. Viruses 7 (5), 645-658.

Pappas, P.A., DePuy, V., 2004. An overview of non-parametric tests in $S_{A}{ }^{\circledR}$ : when, why and how. In: Proc. South East SAS Users Group Conference: Paper TU04.

Shetty, A.K., Peek, L.A., 2012. Peramivir for the treatment of influenza. Expert Rev. Anti. Infect. Ther. 10 (2), 123-143.

Sheu, T.G., Deyde, V.M., Okomo-Adhiambo, M., Garten, R.J., Xu, X., Bright, R.A., Butler, E.N., Wallis, T.R., Klimov, A.I., Gubareva, L.V., 2008. Surveillance for neuraminidase inhibitor resistance among human influenza A and B viruses circulating worldwide from 2004 to 2008. Antimicrob. Agents Chemother. 52 (9), 3284-3292.

Sleeman, K., Guo, Z., Barnes, J., Shaw, M., Stevens, J., Gubareva, L.V., 2013. R292K substitution and drug susceptibility of influenza A(H7N9) viruses. Emerg. Infect. Dis. 19 (9), 1521-1524.

Sleeman, K., Mishin, V.P., Guo, Z., Garten, R.J., Balish, A., Fry, A.M., Villanueva, J., Stevens, J., Gubareva, L.V., 2014. Antiviral susceptibility of variant influenza A(H3N2)V viruses isolated in the United States from 2011 to 2013. Antimicrob. Agents Chemother. 58 (4), 2045-2051.

Takashita, E., Ejima, M., Itoh, R., Miura, M., Ohnishi, A., Nishimura, H., Odagiri, T. Tashiro, M., 2014. A community cluster of influenza A(H1N1)pdm09 virus exhibiting cross-resistance to oseltamivir and peramivir in Japan, November to December 2013. Euro Surveill. 19 (1).

Takashita, E., Kiso, M., Fujisaki, S., Yokoyama, M., Nakamura, K., Shirakura, M. Sato, H., Odagiri, T., Kawaoka, Y., Tashiro, M., 2015a. Characterization of a large cluster of influenza A(H1N1)pdm09 viruses cross-resistant to oseltamivir and peramivir during the 2013-2014 influenza season in Japan. Antimicrob. Agents Chemother. 59 (5), 2607-2617.

Takashita, E., Meijer, A., Lackenby, A., Gubareva, L., Rebelo-de-Andrade, H., Besselaar, T., Fry, A., Gregory, V., Leang, S.K., Huang, W., Lo, J., Pereyaslov, D. Siqueira, M.M., Wang, D., Mak, G.C., Zhang, W., Daniels, R.S., Hurt, A.C., Tashiro, M., 2015b. Global update on the susceptibility of human influenza viruses to neuraminidase inhibitors, 2013-2014. Antivir. Res. 117, 27-38.

Tamura, D., Nguyen, H., Sleeman, K., Levine, M., Mishin, V., Yang. H., Guo, Z., OkomoAdhiambo, M., Xu, X., Stevens, J., Gubareva, L., 2013. Cell culture-selected substitutions in influenza $\mathrm{A}(\mathrm{H} 3 \mathrm{~N} 2)$ neuraminidase affect drug susceptibility assessment. Antimicrob. Agents Chemother. 57 (12), 6141-6146.

Tisdale, M., 2000. Monitoring of viral susceptibility: new challenges with the development of influenza NA inhibitors. Rev. Med. Virol. 10 (1), 45-55.

Tocris Website http://www.tocris.com/molarityCalculator.php. (accessed 09.10.15.).

Wetherall, N.T., Trivedi, T., Zeller, J., Hodges-Savola, C., McKimm-Breschkin, J.L. Zambon, M., Hayden, F.G., 2003. Evaluation of neuraminidase enzyme assays using different substrates to measure susceptibility of influenza virus clinical isolates to neuraminidase inhibitors: report of the neuraminidase inhibitor susceptibility network. J. Clin. Microbiol. 41 (2), 742-750.

World Health Organization, 2012. Meetings of the WHO working group on surveillance of influenza antiviral susceptibility - Geneva, November 2011 and June 2012. Wkly. Epidemiol. Rec. 87 (39), 369-374.

Yamashita, M., Tomozawa, T., Kakuta, M., Tokumitsu, A, Nasu, H., Kubo, S., 2009. CS8958, a prodrug of the new neuraminidase inhibitor R-125489, shows longacting anti-influenza virus activity. Antimicrob. Agents Chemother. 53 (1) $186-192$. 
SUPPLEMENTAL TABLES

Supplemental Table S1. Fluorescent NI assay IC 50 values for CDC Neuraminidase Inhibitor Susceptibility Reference Virus Panel version 2.0 ${ }^{a}$

\begin{tabular}{lccc}
\hline \multirow{2}{*}{ Virus Name } & $\begin{array}{c}\text { Influenza } \\
\text { Type/Subtype }\end{array}$ & \multicolumn{2}{c}{$\begin{array}{c}\text { IC50 (nM) } \\
\text { Mean } \pm \text { SD (Fold Change })^{\boldsymbol{b}}\end{array}$} \\
\cline { 3 - 4 } & & Oseltamivir & Zanamivir \\
\hline A/California/12/2012 Wildtype & $\mathrm{A}(\mathrm{H} 1 \mathrm{~N} 1)$ pdm09 & $0.20 \pm 0.07(1)$ & $0.13 \pm 0.06(1)$ \\
A/Texas/23/2012 H275Y & $\mathrm{A}(\mathrm{H} 1 \mathrm{~N} 1)$ pdm09 & $174.91 \pm 18.58(875)$ & $0.17 \pm 0.02(1)$ \\
A/Washington/01/2007 & $\mathrm{A}(\mathrm{H} 3 \mathrm{~N} 2)$ & $0.08 \pm 0.01(1)$ & $0.96 \pm 0.25(1)$ \\
A/Texas/12/2007 E119V & $\mathrm{A}(\mathrm{H} 3 \mathrm{~N} 2)$ & $44.72 \pm 7.15(559)$ & $0.37 \pm 0.02(1)$ \\
B/Rochester/02/2001 Wildtype & $\mathrm{B}$ & $7.34 \pm 0.98(1)$ & $0.74 \pm 0.06(1)$ \\
B/Rochester/02/2001 D198N & $\mathrm{B}$ & $38.44 \pm 4.48(5)$ & $5.54 \pm 0.83(7)$ \\
B/Memphis/20/96 Wildtype & $\mathrm{B}$ & $4.25 \pm 1.51(1)$ & $1.01 \pm 0.09(1)$ \\
B/Memphis/20/96 R152K & $\mathrm{B}$ & $646.17 \pm 90.32(152)$ & $46.60 \pm 8.39(46)$ \\
\hline
\end{tabular}

Abbreviations - SD: Standard deviation

${ }^{a}$ Source: CDC Neuraminidase Inhibitor Susceptibility Reference Virus Panel (version 2.0) - Product Information Sheet and Instructions for Use.

${ }^{b}$ Fold difference in $\mathrm{IC}_{50}$ determined by dividing the $\mathrm{IC}_{50}$ for the type/subtype-specific variant virus by that of the corresponding wildtype matching virus. 
Supplemental Table S2. Median fluorescent NI assay IC50s of oseltamivir, zanamivir and peramivir obtained by the three NSRCIs (CDPH, USLPH and WSLH) and the CDC for U.S. influenza A and B surveillance isolates circulating during the 2011-15 influenza seasons

\begin{tabular}{|c|c|c|c|c|c|c|c|c|c|c|c|c|c|c|c|c|c|}
\hline \multirow{3}{*}{ NAI } & \multirow{3}{*}{$\begin{array}{c}\text { Influenza Type/ } \\
\text { Subtype }\end{array}$} & \multicolumn{16}{|c|}{ Median IC $_{50}(\mathrm{nM})$, by influenza season } \\
\hline & & \multicolumn{4}{|c|}{$2011-12(n=2767)^{a}$} & \multicolumn{4}{|c|}{$2012-13(\mathrm{n}=2915)^{b}$} & \multicolumn{4}{|c|}{$2013-14(n=3681)^{c}$} & \multicolumn{4}{|c|}{$2014-15(\mathrm{n}=3033)^{d}$} \\
\hline & & CDPH & USLPH & WSLH & CDC & CDPH & USLPH & WSLH & CDC & CDPH & USLPH & WSLH & CDC & CDPH & USLPH & WSLH & CDC \\
\hline \multirow[b]{2}{*}{ Oseltamivir } & A(H1N1)pdm09 & 0.17 & 0.16 & 0.12 & 0.19 & 0.21 & 0.14 & 0.10 & 0.17 & 0.16 & 0.19 & 0.13 & 0.20 & 0.17 & 0.11 & 0.12 & 0.21 \\
\hline & $\mathrm{A}(\mathrm{H} 3 \mathrm{~N} 2)$ & 0.09 & 0.11 & 0.07 & 0.11 & 0.09 & 0.11 & 0.08 & 0.13 & 0.10 & 0.15 & 0.11 & 0.14 & 0.11 & 0.10 & 0.10 & 0.15 \\
\hline \multirow{3}{*}{ Zanamivir } & $\mathrm{A}(\mathrm{H} 1 \mathrm{~N} 1) \mathrm{pdm} 09$ & 0.11 & 0.16 & $--^{e}$ & 0.18 & 0.12 & 0.18 & 0.12 & 0.19 & 0.13 & 0.21 & 0.16 & 0.19 & 0.14 & 0.17 & 0.15 & 0.21 \\
\hline & A(H3N2) & 0.15 & 0.23 & -- & 0.25 & 0.17 & 0.26 & 0.17 & 0.26 & 0.18 & 0.30 & 0.22 & 0.20 & 0.15 & 0.23 & 0.20 & 0.20 \\
\hline & B & 0.76 & 1.08 & -- & 1.19 & 1.02 & 1.00 & 0.69 & 1.05 & 0.58 & 0.89 & 0.77 & 0.73 & 0.98 & 0.80 & 0.58 & 0.84 \\
\hline \multirow{3}{*}{ Peramivir } & A(H1N1)pdm09 & 0.05 & 0.06 & 0.03 & 0.05 & $--^{f}$ & -- & -- & 0.07 & 0.04 & 0.07 & 0.05 & 0.06 & 0.05 & 0.06 & 0.06 & 0.08 \\
\hline & $\mathrm{A}(\mathrm{H} 3 \mathrm{~N} 2)$ & 0.07 & 0.09 & 0.05 & 0.08 & -- & -- & -- & 0.10 & 0.07 & 0.12 & 0.08 & 0.09 & 0.07 & 0.08 & 0.07 & 0.09 \\
\hline & $\mathrm{B}$ & 0.43 & 0.55 & 0.27 & 0.40 & -- & -- & -- & 0.39 & 0.35 & 0.48 & 0.35 & 0.35 & 0.46 & 0.41 & 0.37 & 0.44 \\
\hline
\end{tabular}

